\title{
Systematic Errors in Service Speed
}

\author{
J. M. Irvine
}

I. Introduction. An accurate knowledge of the service speed of a merchant vessel is becoming increasingly important. Service speed and average speed (the former traditionally implying a long-term average, the latter a short-term average) are both derived by dividing the sum of a number of observed distances by the relevant time elapsed. In this way fluctuations in observed distances arising from random fix errors and the effects of change of draught, weather and variable currents are smoothed. Service speed may be used as a basis for determining log errors, engine efficiencies, hull surface condition, liner schedules and charter party speeds. It is therefore relevant to consider possible systematic errors which may be introduced in the calculation of these speeds.

2. UNITS OF SPEED AND DISTANCE. Only in measured-mile trials are speeds calculated in terms of a standard distance. In service, observed distances and speeds are traditionally calculated in units of minutes of latitude. This variable unit is $\mathrm{I} \cdot \circ$ per cent greater at the poles than at the equator due to the spheroidal figure of the Earth. Williams, 1 Sadler ${ }^{2}$ and Turner ${ }^{3}$ have shown how distances may be calculated in units of a standard nautical mile, but none of these methods have been generally accepted for use at sea. Burton ${ }^{4}$ published Williams' handy table for correcting traditional mercator calculations, but omitted it in later editions after Moody 5 had discussed the variety in the standard nautical miles then in use. With the adoption of the International mile of 1852 metres 6 this table would be applicable if resulting distances were increased by 0.06 per cent.

Alternatively, the systematic error inherent in using the variable unit of a minute of latitude may be calculated thus :

Error (per cent $)=100\left(1-l(\phi) / 185^{2}\right)$

where

$l(\phi)=\{\pi a /(180 \times 60)\}\left\{1-e^{2} / 4-\frac{3}{64} e^{4}-\frac{3}{4}\left(e^{2}+e^{4} / 4\right) \cos 2 \phi+\frac{15}{64} e^{4} \cos 4 \phi\right\}$ $=1852 \cdot 20-9.48 \cos 2 \phi+0.20 \cos 4 \phi \quad$ (Clarke, 1880 )

$=1852.28-9.37 \cos 2 \phi+0.20 \cos 4 \phi \quad$ (Int. spheroid)

Either relationship will provide the following corrections to conventional 'average speeds' to obtain speeds in International knots :

TABLE I. Correction in knots for length of minute of latitude

\begin{tabular}{|c|c|c|c|c|c|}
\hline \multirow{2}{*}{$\begin{array}{l}\text { Observed } \\
\text { speed (kt.) }\end{array}$} & \multicolumn{5}{|c|}{ Latitude } \\
\hline & $0^{\circ}$ & $15^{\circ}$ & $30^{\circ}$ & $45^{\circ}$ & $60^{\circ}$ \\
\hline 15 & -0.07 & -0.06 & -0.04 & 0 & +0.04 \\
\hline 25 & -0.12 & -0.10 & -0.06 & 0 & +0.07 \\
\hline
\end{tabular}


3. Method of calculation. The corrections above are applicable to all average speeds regardless of which 'sailing' is used for the distance calculations. The relative merits of mercator/mid-latitude calculations vis-a- - is mean latitude calculations is an old argument.7 For average speed purposes the mercator calculation is often advocated as being aesthetically 'more accurate' and being commercially more advantageous (since it gives apparently faster speeds). However, when the course exceeds $85^{\circ}$ from the meridian other methods must be used 4 and when there have been several alterations of course other methods may be justified because of the probability of random calculation errors. It is thus relevant to compare the reliability of speeds derived from the two principles.

The systematic errors in average speeds derived from the mean latitude method are complex functions. Moss's diagrams 8 indicate that for runs of 24 hours in latitudes of less than $60^{\circ}$ the errors are zero on N./S. and a maximum on E./W. courses. The following maximum corrections to obtain traditional 'mercator' speeds have been interpolated by eye:

TABLE II. Maximum correction for mean-latitude calculation

\begin{tabular}{c|c|c|c|c|c}
\hline $\begin{array}{c}\text { Observed } \\
\text { speed (kt.) }\end{array}$ & \multicolumn{5}{|c}{ Latitude } \\
\cline { 2 - 5 } & $0^{\circ}$ & $15^{\circ}$ & $30^{\circ}$ & $45^{\circ}$ & $60^{\circ}$ \\
\hline 15 & +0.10 & $\begin{array}{l}+0.08 \\
+0.15\end{array}$ & $\begin{array}{l}+0.07 \\
+0.12\end{array}$ & $\begin{array}{l}+0.06 \\
+0.08\end{array}$ & $\begin{array}{l}+0.03 \\
+0.04\end{array}$ \\
\hline
\end{tabular}

To express average speeds derived by the mean latitude calculation in International knots the two corrections must be combined, thus :

TABLE III. Combined correction in knots for mean latitude calculation

\begin{tabular}{|c|c|c|c|c|c|c|}
\hline \multirow{3}{*}{$\begin{array}{l}\text { Observed } \\
\text { speed }(k t .)\end{array}$} & \multicolumn{6}{|c|}{ Latitude and course } \\
\hline & \multicolumn{2}{|c|}{$0^{\circ}$} & \multicolumn{2}{|c|}{$15^{\circ}$} & \multicolumn{2}{|c|}{$30^{\circ}$} \\
\hline & N./S. & E. $/ W$. & N./S. & E./W. & N./S. & E. $/ W$. \\
\hline \multirow{3}{*}{$\begin{array}{l}15 \\
25\end{array}$} & -0.07 & +0.03 & -0.06 & +0.02 & -0.04 & +0.03 \\
\hline & -0.12 & +0.05 & -0.10 & +0.05 & -0.06 & +0.06 \\
\hline & \multicolumn{2}{|r|}{$\begin{array}{l}\quad 45^{\circ} \\
\text { NW. NE. } \\
\text { SW. SE. }\end{array}$} & E. $/ W$. & N./S. & $\begin{array}{l}6^{\circ} \\
\text { NW. NE. } \\
\text { SW. SE. }\end{array}$ & E./W. \\
\hline I5 & 0.00 & -0.02 & +0.06 & +0.04 & +0.04 & +0.07 \\
\hline 25 & 0.00 & 0.00 & +0.08 & +0.07 & +0.03 & +0.11 \\
\hline
\end{tabular}

4. Conclusions. Tables I and III provide a quantitative means of assessing several commonly made assumptions. In particular it can be seen that:

(i) For practical purposes it is quite adequate to calculate average speed by mean latitude sailing and to assume a minute of latitude is equivalent to any standard nautical mile. 
(ii) The traditional calculation of average speed to two places of decimals is misleading unless the relevant corrections have been included. The second decimal place was doubtless originally introduced to avoid a rounding error which has an amplitude equivalent in distance to $2 \frac{1}{2}$ miles, in a 24-hour run. Present knowledge of random position errors make such accuracy unjustified over a single 24 -hour period and it can be seen that systematic errors are unlikely to justify the second place when such runs are summed.

(iii) The statistical analysis of service speed is liable to be erroneous without knowledge of how the speeds have been calculated.

(iv) The theoretical advantages of mercator sailing over mean latitude sailing are shown to be severely qualified when used for average speed calculations without the necessary correction. For distances of up to 600 miles, uncorrected mercator methods result in greater systematic errors except when the latitude is greater than about $45^{\circ}$ and the course is between about $45^{\circ}$ and $85^{\circ}$ from the meridian.

\title{
REFERENCES
}

1 Williams, J. E. D. (1950). Loxodromic distances on the terrestrial spheroid. This Journal, 3, 133 .

2 Sadler, D. H. (1956). Spheroidal sailing and middle latitude. This Journal, 9, 37 I.

3 Turner, R. J. (1970). Rhumb-line sailing with a computer. This Journal, 23, 233.

4 Burton, S. M. (1951). Nautical Tables, Tables 3 and 3 a, 4 th Edition. G. Philip \& Son.

5 Moody, A. B. $\left(195^{2}\right)$. Early units of measurements and the nautical mile. This Journal, 5,262

6 Ritchie, G. S. (1970). Comment on 'Metrication and the nautical mile'. This Journal, 23, 388 .

7 Llewellyn, M. R. H. (1970). Rhumb-line and great-circle sailings. This Journal, 23, 119.

8 Moss, B. J. (1969). Exploration with a computer on rhumb-line sailing. This Journal, 22, $24^{2}$.

\section{High-Speed Vessels and the Collision Regulations}

\author{
Captain G. H. Draysey \\ (Hydrofoil Commander)
}

IT has become increasingly apparent that there is a pressing need to amend the Collision Regulations with special regard for the requirements of high-speed vessels. My experience as a Commander of a hydrofoil on a scheduled passenger service, in an area of high traffic density, has led me to write this paper and to add weight to the argument in favour of an early alteration of the existing Rules.

There are more and more types of vessel today capable of speeds in excess of 40 and indeed up to 60 or more knots. In the Solent area alone, there are two hovercraft services and a hydrofoil service. In addition there are the experimental 